\title{
BASIC ACTIONS TO REDUCE DROPOUT RATES IN DISTANCE LEARNING
}

Authors:

Pablo Gregori, PhD (Corresponding Author)

Universitat Jaume I de Castellón, Dept. Matematicas,

Instituto Universitario de Matemáticas y Aplicaciones de Castellón,

Campus Riu Sec s/n, Castellón de la Plana,

Castellón, ES 12071 Spain

Email: gregori@uji.es

Vicente Martínez, PhD

Universitat Jaume I de Castellón, Dept. Matematicas,

Instituto Universitario de Matemáticas y Aplicaciones de Castellón,

Campus Riu Sec s/n, Castellón de la Plana,

Castellón, ES 12071 Spain

Email: martinez@uji.es

\section{Julio José Moyano-Fernández, PhD}

Universitat Jaume I de Castellón, Dept. Matematicas,

Instituto Universitario de Matemáticas y Aplicaciones de Castellón,

Campus Riu Sec s/n, Castellón de la Plana,

Castellón, ES 12071 Spain

Email: moyano@uji.es 


\title{
BASIC ACTIONS TO REDUCE DROPOUT RATES IN DISTANCE LEARNING
}

\begin{abstract}
Today's society, which is strongly based on knowledge and interaction with information, has a key component in technological innovation, a fundamental tool for the development of the current teaching methodologies. Nowadays, there are a lot of online resources, such as MOOCs (Massive Open Online Courses) and distance learning courses. One aspect that is common to all of these is a high dropout rate: about $90 \%$ in MOOCs and $50 \%$ in the courses of the Spanish National Distance Education University, among other examples. In this paper, we analyze a number of actions undertaken in the Master's Degree in Computational Mathematics at Universitat Jaume I in Castellón, Spain. These actions seem to help decrease the dropout rate in distance learning; the available data confirm their effectiveness.
\end{abstract}

\section{Keywords}

Distance learning, dropout rate, information and communication technologies in education

\section{Introduction}

Over the past few decades, there has been a dramatic upsurge in online education. This is supported by the following facts: every year the number of students in this type of education increases by around 5\%; during the 2016/2017 academic year, the MIT (Massachusetts Institute of Technology) offered more than 2300 distance courses, with over 200 million visitors; and the University of Harvard has 360,000 foreign students following this type of course. There is no doubt that universities that wish to use new technologies to increase their visibility and teaching quality must try to keep up with the world's leading universities (see Harvard University, 2016; MIT, 2016).

These methodologies are breaking old barriers, which were insurmountable in the past, such as distance and the difficulty of instantly disseminating and exchanging knowledge. The creation of virtual learning environments opens a window to the world for the dissemination and design of efficient methodologies for conveying knowledge, as well as being an economically sustainable option.

One of the strengths of the Master's Degree in Computational Mathematics (MUMC) at Universitat Jaume I (UJI) in Castellón is its online enrolment system; in fact, more than half of the students enroll in the distance course. Particular care must therefore be taken with the "teacher-student" relationship in this group, mainly in terms of the learning process and its evaluation. However, the 
implementation of such a procedure in the Spanish university system has certain drawbacks that prevent an optimal praxis of this methodology in distance learning groups.

An important aspect that needs to be considered in distance learning is the high percentage of students who drop out after starting their studies. The National Distance Education University (UNED - Universidad Nacional de Educación a Distancia), a Spanish state university that was created in the 1970s, has for years monopolized distance education in Spain. However, it did not offer $100 \%$ distance education, since a face-to-face system of office hours was also organized. In the nineties, the Autonomous Community of Catalonia created the Universitat Oberta de Catalunya (UOC), incrementing the options for distance education. But the growth has been exponential during the last decade, thanks to institutions like Universidad a Distancia de Madrid, Universidad Internacional de Valencia, Universidad Internacional de La Rioja and Universidad Isabel I among many many others. The UNED has published some data (see de Santiago, 2017) that may be useful for examining the reasons why many students drop out after their initial enrolment; this is the case when students who enroll for a whole academic year do not re-enroll the following year. The UNED has identified this particular group, since the vast majority of students who drop out do so within this context.

The analysis was carried out as a result of changes in the curricula that took place after 2010. It can be clearly observed that the weak point of distance education is the high dropout rate. Table 1 shows these percentages for a number of degree programs. Very high rates are observed in all the subjects, whether sciences or humanities. 


\begin{tabular}{|l|l|}
\hline Degree & Dropout rate \\
\hline Chemistry* & $64.5 \%$ \\
\hline Mechanical Engineering & $61.6 \%$ \\
\hline Electrical Engineering & $60.5 \%$ \\
\hline Physics* & $59.7 \%$ \\
\hline Industrial Electronic and Automation Engineering & $57.1 \%$ \\
\hline Mathematics* & $55.8 \%$ \\
\hline Philosophy & $46.6 \%$ \\
\hline Economics & $45.9 \%$ \\
\hline Political and Administrative Sciences & $42.1 \%$ \\
\hline Geography and History & $40.3 \%$ \\
\hline Social Education & $38.0 \%$ \\
\hline English & $35.9 \%$ \\
\hline Psychology & $33.5 \%$ \\
\hline History of Art & $31.2 \%$ \\
\hline
\end{tabular}

Table 1. Dropout rates after initial enrolment for UNED degrees in 2010, according to De Santiago (2017). Studies marked with * correspond to data of the year 2008.

In the case of MOOCs, Chapman et al. (2016) suggested performance monitoring indicators to detect the level of engagement of participants, since it is a good predictor of learning success, while DeBoer et al. (2014) pointed out the existence of other important unmeasured factors for this success.

The most significant fact that can be observed is that the dropout rate is one of the main concerns of many national European education systems. For instance, Oppedisano (2009) relates graduation rates in European countries to the policy of open admission. Also, the report European Commission (2015) reviews the definitions and policies of study success across Europe, proposing strategies at multiple scopes (funding, organizational, staff, etc.). Regarding Spain, Rué (2014) relates the dropout rate to the interaction between university and society at the social, cultural and economical levels, and the report CRUE (2014) provides with descriptive statistics of the situation.

In this work, our aim is to design and analyze the implementation of a number of guidelines that allow us to effectively unify a high-quality teaching methodology and the use of new technologies in distance learning. The intention is to guide the relationship between teacher and student, establishing a clear, coordinated and evaluable method of action to make any changes that might be needed to improve the learning experience. We will focus on the analysis of the dropout rate to establish patterns of behavior at all levels that allow us to decrease this indicator. 


\section{Dropout rate}

This indicator supplies annual information about the number of students who leave their degrees with respect to the number of students initially enrolled. The precise definition of this indicator varies from one institution to another.

At UJI, the formula used to compute this rate is as follows: the percentage of students in an entry cohort $\mathrm{C}$ enrolled in the degree program in the academic year X-2 who have not enrolled in that degree in the years $\mathrm{X}-1$ and $\mathrm{X}$, over the total number of students in entry cohort $\mathrm{C}$ who started said degree program in the academic year X-2. The academic year X is the academic year for which the calculations are made.

$$
\text { "Dropout rate" indicator }=(\mathrm{V} 1 / \mathrm{V} 2) * 100
$$

where

- $\mathrm{V} 1=$ Number of newly enrolled students who enrolled in academic year X-2 but not in X-1 and $\mathrm{X}$.

- $\quad \mathrm{V} 2=$ Number of newly enrolled students for the academic year X-2.

In Fig.1, the dropout rate according to the formula (1) is given for the MUMC. The percentages corresponding to the 2011/2012,2012/2013,2013/2014 and 2014/2015 academic years are not considered statistically significant, due to the low number of students in those years. The only statistically significant value is the one corresponding to the $2015 / 2016$ academic year.

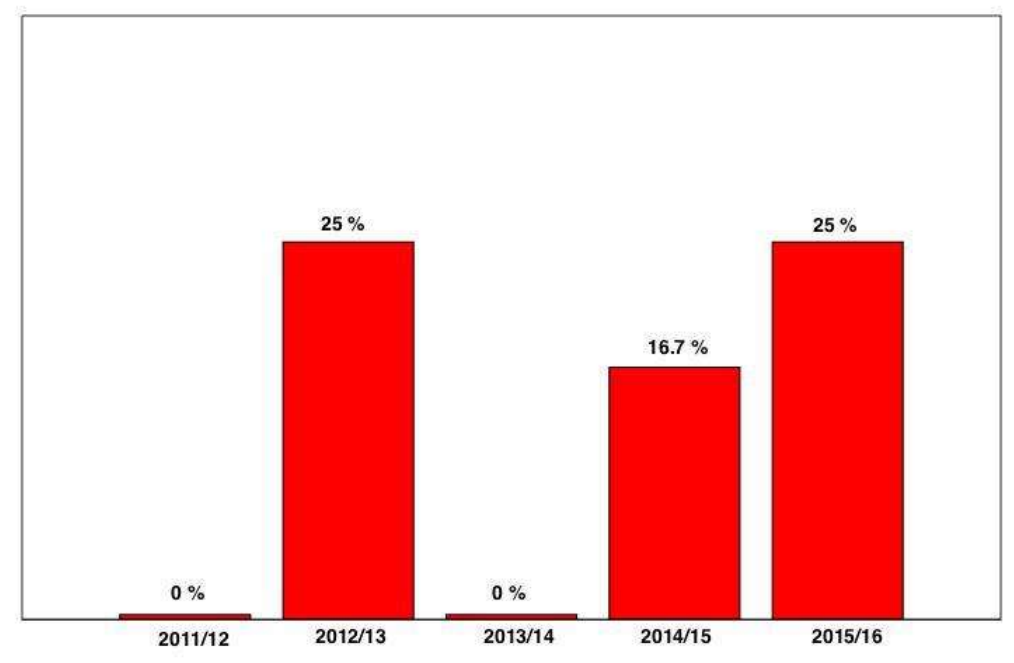

Figure 1. Dropout rates per academic year for the MUMC. Data obtained from the Quality Management Service at UJI. 
Figure 2 shows dropout rates at UJI per academic year and for different levels (undergraduate degree, master's degree, online master's degree). It can be observed that on-campus (i.e. not online) undergraduate degrees have a slightly higher dropout rate than master's degrees. This may be explained, among other factors, by the lower level of maturity in terms of personal development, as well as the fact that those courses are four times longer (the duration of an undergraduate degree in the Spanish system is four years, whereas a master's degree only lasts for one year). In addition, it can be observed that the online master's program has a higher dropout rate than that of the oncampus master's program. Among other reasons, this may be due to the need for more specific learning material or a suitable Internet connection (which cannot currently be assumed for everyone in Spain), or the difficulty of distance learning, etc.

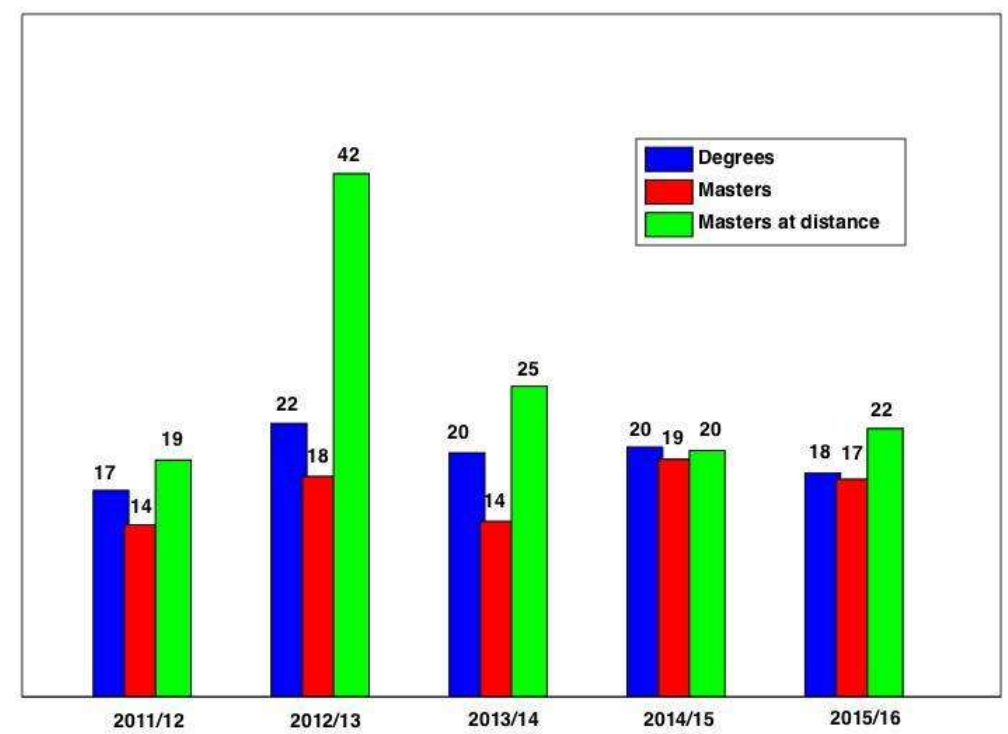

Figure 2. Average dropout rate for studies at UJI per academic year and type of course. Data obtained from the Quality Management Service at UJI.

Regarding the 2015/2016 academic year, the only year for which we consider the data to be significant, the difference between the rate for the MUMC and the average rate for all other master's courses is negligible ( $25 \%$ vs. $22 \%$ ). Among other possible factors, inherent to the nature of disciplines, Tab. 1 leads us to ponder on the difficulty of distance learning, in the case of scientific and technical subjects, as an important explanatory factor.

As pointed out in the introduction, the dropout rate is one of the main concerns of many national European education systems. Therefore, it is important to study and analyze it, as well as to implement actions to improve the current rates. In this regard, in the following sections we will outline some guidelines that should be adopted to reduce the dropout rate. 


\section{Methodological guidelines to reduce dropout rates}

\section{Initial contact}

The opening of the new semester is a decisive moment for establishing a link between teacher and student. It is a distance learning student's first point of engagement with the subject. For this reason, it is recommended that the teacher should set up an in-person or virtual joint session on the first day of the semester, if possible with all the students. This session should motivate the students with regard to the content of the subject and establish guidelines for the relationship between teachers and students in order to involve all students in the subject, including those who could not even attend this first session. One feasible proposal is to broadcast (and record) the session by videoconference. It is essential that distance learning students should feel part of the subject from the beginning. The date and time of this first session should be agreed upon with all those involved in order to ensure the greatest possible number of participants.

\section{Tutoring}

The gateway to the course for distance learning students is the subject's "Virtual Classroom". This space should be used to provide news, announcements, useful and/or recommended teaching material, etc. An additional effort should be made to keep the Virtual Classroom up to date, since it is the only means of contact with the subject for distance learning students.

Office hours, both virtual and face-to-face, are essential to ensure that students do not stop learning their subjects. Teachers should be aware of this, as it can be an effective way to attract students' attention and interest. In the case of virtual office hours, a pre-set weekly schedule must also be provided in order to be accessible to students. Virtual office hours may be based on answering questions by e-mail, but they could also be carried out by videoconference or some other means, depending on the available resources (the reader is referred to Gregori and Martínez, 2017, for further information).

\section{Continuous assessment}

The current trend in university teaching is to assign part (or all) of the learning assessment to objective tests throughout the semester. These tests can take different forms:

- Written examinations about contents related to the subject being taught.

- Oral presentations about the course contents or that complement these.

- Written essays in which the student shows their understanding of lecture topics. Or optionally of supplementary material or applications of the topics to other fields. 
- Exercises or problem solving worksheets, practical examples about the contents explained during the lectures or supplementary subjects, or even reviews of topics considered as previous knowledge.

The frequency of continuous assessment should be proportional to the effort invested in it, trying not to overload the student so that it does not interfere with their performance in the other subjects within the master's program. For further details, see Gregori et al. (2016).

\section{Final assessment}

The final assessment consists of both the result of continuous assessment and a final examination, although none of these should be mandatory. The final examination depends on the system that each teacher proposes in coordination with the whole teaching staff. This must be clearly stated in the teaching guide and must be in line with all the established documents (e.g. the "degree verification report" in the Spanish system).

In order to ensure fairness in the process of oral examinations, teachers are required to complete a file containing the following information:

- Name and surname(s) of the examinee, as well as his/her passport number.

- Name and surname(s) of the examiner(s).

- A clear description of how the test is carried out.

- How the oral test is graded, with detailed reasoning.

All this must be recorded and saved to avoid misunderstandings, complaints and grades that are difficult to justify. In written tests, the examination itself will be considered the protocol that guarantees for a fair assessment. Assessment protocols are an effective measure for the defense of both the teacher and the student against potential abuse or injustice of any party, or interference from third parties.

\section{Guarantees regarding the identity of the assessed students}

A major of drawback distance learning courses is the reliable verification of the identity of the student performing the different activities and tasks suggested throughout the course. The committee responsible for managing the undergraduate or master's degree should require students to prove their identity. If there was an agreement with other universities, this accreditation could be carried out by them. There would be teachers responsible for this task, both at the university issuing the degree and at the university where the student would have to present proof of identity. The required tests could be carried out by videoconference (or by any other available technical means). If the student did not belong to an institution collaborating with the university issuing the degree, and if the faculty had any doubts about the student's identity at the time of the assessment, the 
student would have to take a face-to-face test at the university issuing the degree. To this end, the following procedure is established:

- Before finishing the teaching semester, the master's faculty will draw up a list with the students who will have to take this test.

- The tests will take place on three specific days for all the subjects during the first nonteaching week of the master's course so that the student does not need to be away from home for too long.

- For the students to defend their Master's Thesis (Final Project), depending on the origin and availability of the candidate, the following order of preference is proposed:

- In person at the university issuing the degree.

- By videoconference or similar means, specifying the place where the candidate must be present.

\section{Conclusions}

The experience gained from the aforementioned master's course has shown that following certain rules of best practice has helped create an effective learning environment. To create an environment of closeness and co-responsibility it is necessary to maintain respect between faculty and students in terms of manners and personal attention, as well as respect for individual idiosyncrasies. On the other hand, the evaluation must be based on criteria of justice and equality. The teaching staff must assume that distance learning students are essentially different from conventional face-to-face students and they have particular difficulties, which can sometimes lead to misunderstandings. In this regard, it is recommendable to maintain fluid communications, especially in the presentation of the course, to create a strong link that will ensure the student does not to feel alone and unattended. We would like to point out that the implementation of these measures has contributed to a reduction of approximately $25 \%$ in the dropout rate of MUMC students. At UJI, an estimate of this rate can be consulted in November of each year, and an exact calculation is made in December. The effectiveness of these practices was verified as follows: once the first estimate (50\%) was known, it was agreed through coordination meetings of the teachers that the aforementioned actions should be implemented. In particular, sending messages and reminders through emails and the Virtual Classroom was quite an effective way to attract the attention and interest of students, as was offering personalized virtual office hours to complete unfinished tasks that some students had not completed by the stipulated deadline. Above all, they were reminded that they were not alone. In view of the involvement shown by the teaching staff, many of the students reacted positively and the result was magnificent, since the definitive calculation of the dropout rate in December turned out to be $25 \%$. 


\section{Lessons learned}

By way of a conclusion, we attach a summary of the guidelines for action that we follow in the MUMC with distance learning students (see Gregori et al., 2016):

1. Encourage distance learning students to attend the first class of the course, either in person or via videoconference.

2. Keep the course page in the Virtual Classroom up to date and send out news and announcements regularly according to the activities proposed.

3. Encourage virtual office hours (see Gregori and Martínez, 2017).

4. Encourage frequent (but not overloaded) continuous assessment (if contemplated).

5. Provide written reports of oral assessment tests (if applicable) that guarantee the fairness of the process.

6. The Master's Thesis will be defended face-to-face at the institution, whenever feasible. If students are unable to attend, they will defend their thesis by videoconference.

7. Be flexible. Problems inherent to distance learning require the faculty to maintain a sympathetic attitude and fluid communications in order to avoid and solve misunderstandings.

\section{Funding}

This work has been partially supported by the Educational Support Unit (USE - Unidad de Soporte Educativo) of Universitat Jaume I de Castellón (grants 3227/16, 3228/16 and 3224/16).

\section{References}

Castañeda J (2016) Movilidad Virtual en el Máster en Matemática Computacional, PhD Thesis, Universitat Jaume I, Spain.

Chapman SA, Goodman S, Jawitz J, Deacon A (2016) A strategy for monitoring and evaluating massive open online courses. Evaluation and Program Planning, 57, 55-63.

CRUE Universidades Españolas (2014). La Universidad Española en cifras 2014-2015. ISBN 97884-617-5297-3. http://www.crue.org/Documentos\%20compartidos/Publicaciones/Universidad \%20Espa\%C3\%B1ola\%20en\%20cifras/UEC_14-15.pdf

DeBoer J, Ho AD, Stump GS and Breslow L (2014) Changing course: reconceptualizing educational variables for massive open online courses. Educational Researcher, 43, 74-84. 
European Commission (2015) Dropout and completion in higher education in Europe. Publications Office of the European Union, Luxembourg. DOI 10.2766/826962.

Gregori and Martínez (2017) Challenges Regarding Scientific Transcription in Virtual Office Hours, submitted.

Gregori, Martínez and Moyano-Fernández (2016) Protocolo de Actuación para el Seguimiento del Alumnado en Cursos Semipresenciales. In: Avances en Tecnologías, Innovación y Desafios de la Educación Superior ATIDES 2016. (ed A Arnal, J Castelló, I Epifanio, C Galindo, P Gregori, AM Lluch \& V Martínez), Castellón de la Plana, Spain, October 2016, pp. 115-120. Castellón de la Plana: Publicacions de la Universitat Jaume I.

Harvard University (2016) About Harvard. Available at: http://www.harvard.edu/about-harvard (accessed June 2016).

MIT (2016) About OCW. Available at: https://ocw.mit.edu/about (accessed June 2016).

Oppedisano V (2009) Open University Admission Policies and Drop Out Rates in Europe. Working Papers 200944, Geary Institute, University College Dublin. Available at: http://www.ucd.ie/geary/static/publications/workingpapers/gearywp200944.pdf

Rué J (2014) El abandono universitario: variables, marcos de referencia y políticas de calidad. REDU Revista de Docencia Univeritaria, 12(2), 281-306.

De Santiago C (2011) El abandono en primera matrícula en la UNED: análisis comparado de la primera cohorte de Grados. In: Portal UNED. Available at: http://portal.uned.es/pls/portal/docs/PAGE/UNED_MAIN/LAUNIVERSIDAD/ VICERRECTORADOS/CALIDAD_E_INTERNACIONALIZACION/ INNOVACION_DOCENTE/IUED/INSTITUCIONAL/ ABANDONOPRIMERAMATRICULAUNED.PDF (accessed February 2017).

Sein-Echaluce ML, Boal N, Bueno C, Castelló J, Correas JM, Gil J, Leris D and Martínez V (2009) From traditional to e- learning via b-learning: optional or necessary? In: 3rd International Technology, Education and Development Conference, Valencia, Spain, 9-11 March, 2009, pp. 5173-5181. 
Vidal I, Martínez V, Castelló J (2009) A blended learning experience on teaching mathematics. In: 3rd International Technology, Education and Development Conference, Valencia, Spain, 9-11 March, 2009, pp. 2241-2246. 